\title{
Transplante cardíaco no Instituto Dante Pazzanese de Cardiologia: análise da sobrevida
}

\author{
Marco Aurélio Salles ASSEF*, Paulo Fernando MF VALBUENA*, Marcondes Tavares NEVES Jr.*, \\ Edileide Barros CORREIA*, Marcos VASCONCELOS*, Ricardo MANRIQUE*, Hélio M. de \\ MAGALHÃES*, Luiz Carlos Bento de SOUZA*; Paulo CHACCUR*, Jarbas J. DINKHUYSEN*
}

RBCCV 44205-557

Assef M A S, Valbuena P F M F, Neves Jr. M. T, Correia E B, Vasconcelos M, Manrique R, Magalhães H M, Souza L C B, Chaccur P, Dinkhuysen J J - Transplante cardíaco no Instituto Dante Pazzanese de Cardiologia: análise da sobrevida. Rev Bras Cir Cardiovasc 2001; 16(4): 289-304

RESUMO: Casuística e Métodos: Foram analisados, retrospectivamente, 80 transplantes cardíacos realizados no Instituto Dante Pazzanese de Cardiologia (IDPC) no período de novembro de 1991 a agosto de 2000. Houve predomínio do sexo masculino em $70 \%$ dos casos e a idade variou de 7 a 69 anos, com média de 44,8 anos. Doze (15\%) pacientes se encontravam em prioridade, em uso de drogas inotrópicas endovenosas no momento do transplante. As etiologias determinantes da insuficiência cardíaca congestiva grave foram: miocardiopatia dilatada idiopática em $37,5 \%$, miocardiopatia isquêmica em $33,75 \%$, miocardiopatia chagásica em $17,5 \%$ e outras causas em $11,25 \%$. Foram realizados 78 transplantes ortotópicos e 2 heterotópicos. A técnica empregada foi bicaval/bipulmonar em $63,75 \%$, atrial em $27,5 \%$, bicaval/ unipulmonar em $6,25 \%$ e heterotópico em 2,5\%. A mortalidade hospitalar (30 dias) foi de 18,75\%.

Resultados: A sobrevida para o transplante ortotópico em um ano foi de $72,7 \%$, em cinco anos $61,5 \%$ e em sete anos $56,4 \%$. A sobrevida após o transplante foi correlacionada com as variáveis idade, causa de óbito e sexo do doador, e pelo transplante ter sido ou não a primeira cirurgia cardíaca do paciente.

DESCRITORES: Transplante de coração, métodos. Transplante de coração, mortalidade. Transplante de coração, estatística \& dados numéricos.

\section{INTRODUÇÃO}

O número de transplantes cardíacos cresceu muito desde o primeiro caso realizado por BARNARD (1), em 1967, cuja técnica havia sido padronizada por LOWER \& SHUMWAY ${ }^{(2)}$, em 1960.

Novos avanços foram obtidos, em 1972, por CAVES et al. (3) que, através de achados da biópsia endomiocárdica, desenvolveram um sistema de classificação histológica para rejeição. Também foi de grande importância nesta fase inicial a sistematização dos procedimentos para a definição de morte cerebral dos doadores, mas foi somente a partir de
1980 que o transplante cardíaco incorporou-se à rotina terapêutica com o emprego de uma nova droga imunossupressora, a ciclosporina, utilizada pela primeira vez em Stanford (4).

A utilização dos inibidores da enzima conversora da angiotensina determinou impacto importante na melhora da sintomatologia da insuficiência cardíaca congestiva (ICC) e um efeito moderado na sobrevida a longo prazo. Entretanto, para os doentes com ICC em classe IV da New York Heart Association (NYHA) a mortalidade no primeiro ano persiste em torno de $30 \%$ a $40 \%{ }^{(5)}$. A comparação das curvas de mortalidade do paciente mantido em tratamento clínico

Trabalho realizado na Seção Médica de Transplante Cardíaco do Instituto Dante Pazzanese de Cardiologia. São Paulo, SP, Brasil. Recebido para publicação em março de 2001.

*Do Instituto Dante Pazzanese de Cardiologia.

Endereço para correspondência: Marco Aurélio S. Assef. Alameda Lorena, 484, apto. 92. São Paulo, SP, Brasil. CEP 01424-000. Tel/Fax. (11) 55737404.e-mail: marcoassef@sti.com 
Assef M A S, Valbuena P F M F, Neves Jr. M. T, Correia E B, Vasconcelos M, Manrique R, Magalhães H M, Souza L C B, Chaccur P, Dinkhuysen J J - Transplante cardíaco no Instituto Dante Pazzanese de Cardiologia: análise da sobrevida. Rev Bras Cir Cardiovasc 2001; 16(4): 289-304

e daquele submetido ao transplante cardíaco acaba sendo o maior argumento em favor do transplante, fazendo com que o prognóstico da cardiopatia de estágio terminal fosse modificado por este tratamento. Atualmente, é a opção que apresenta meIhor sobrevida para pacientes com ICC grave refratária ao tratamento clínico, chegando a ter mortalidade imediata muito baixa, como na casuística de TRENTO et al. (6).

Estes fatos constataram a aplicabilidade do procedimento, entretanto, este sucesso se depara com uma limitação clínica pela escassez de doadores, determinando aumento das listas de espera. $\mathrm{O}$ registro da International Society for Heart and Lung Transplantation de 1999 (7) chama atenção para esse fato quando incluiu 3673 transplantes cardíacos no último ano, a menor cifra dos últimos cinco anos numa curva já decrescente desde 1996.

Em situações onde as causas determinantes de insuficiência cardíaca não podem ser tratadas clinicamente ou através de operações convencionais, a opção do transplante cardíaco deve ser considerada.

O objetivo deste trabalho é analisar a sobrevida dos pacientes submetidos ao transplante cardíaco no IDPC, correlacionando-a com variáveis dos doadores e receptores, e a partir destas, determinar fatores que influenciam negativamente na sobrevida. As variáveis analisadas do doador foram sexo, idade e a causa da morte encefálica e as do receptor foram faixa etária, sexo, reoperação, prioridade para transplante, diabete, etiologia da ICC, reativação da doença de Chagas e a técnica cirúrgica empregada.

\section{CASUÍSTICA E MÉTODOS}

Foram analisados, retrospectivamente, 80 pacientes submetidos a transplante cardíaco no IDPC no período compreendido entre novembro de 1991e agosto de 2000. O tempo total de observação foi de 105 meses.

O processo de seleção de candidatos se resumiu em identificar pacientes com expectativa de vida limitada, apesar do tratamento clínico otimizado, e que estivessem em classe funcional III ou IV da NYHA. Foram excluídos pacientes que apresentavam contra-indicações preconizadas pela Sociedade Brasileira de Cardiologia para Transplante Cardíaco (8). São os que apresentavam diverticulose, diabetes melito dependente de insulina, infecções ativas, disfunção hepática não secundária a ICC ou renal com clearance de creatinina inferior a $30 \mathrm{ml}$ $\mathrm{K} / \mathrm{min}$. (e não responsiva a testes com drogas inotrópicas), neoplasias, doenças neurológicas, doenças psíquicas, hipertensão pulmonar (resistência vascular pulmonar $>6$ unidades Wood e cujos níveis não caiam para menos de $2,5 \mathrm{U}$ com uso de nitroprussiato de sódio), alcoolismo ou dependência de drogas e a falta de condições socioeconômicas mínimas de manutenção.

Foram consideradas contra-indicações relativas: idade acima de 70 anos, diabetes melito não dependente de insulina, úlcera péptica ativa, embolia pulmonar recente (<3 meses) e obesidade.

Houve predomínio do sexo masculino, com 56 (70 \%) casos, e a idade oscilou de 7 a 69 anos, com média de 44,8 anos.

O transplante ortotópico representou $97,5 \%$ dos casos (77 pacientes), enquanto 2 pacientes foram submetidos ao tipo heterotópico. Houve um retransplante cardíaco.

A etiologia determinante da ICC foi: miocardiopatia dilatada idiopática (MDI) em 30 (37,5\%) casos, miocardiopatia isquêmica (MI) em 27 $(33,88 \%)$, miocardiopatia chagásica (MC) em 14 $(17,5 \%)$ e outras etiologias em 9 (valvar em 5, periparto em 3 e retransplante em 1), com 11,2\% (Gráfico 1). Dos pacientes chagásicos, 4 apresentaram reativação da doença após o transplante, sendo a paciente do retransplante após a $1^{\underline{a}}$ e $2^{\underline{a}}$ operações.

Vinte $(25 \%)$ pacientes já haviam sido submetidos à uma ou mais operações cardíacas prévias, $8(10 \%)$ apresentavam diabetes melito não dependente de insulina (DM) e $12(15 \%)$ se encontravam em prioridade na lista de espera, internados em uso de drogas inotrópicas endovenosas.

A técnica cirúrgica empregada foi a atrial (clássica) em $22(27,5 \%)$ casos, bicaval/bipulmonar em 51 (63,8\%), bicaval/unipulmonar em 5 (6,2\%) e heterotópica em $2(2,5 \%)$ casos, os quais apresentavam hipertensão pulmonar elevada pouco responsiva ao teste com vasodilatador.

A análise estatística relacionada aos doadores se baseou na idade (40 anos como idade de corte), sexo e causa da morte encefálica, isto é, se foi acidente vascular cerebral isquêmico/hemorrágico ou se foi traumatismo/tumor cerebral, sendo estas variáveis cruzadas entre si.

Os doadores se encontravam em situação clínica favorável, e foram selecionados conforme preconizado pelas diretrizes da Sociedade Brasileira de Cardiologia (9).

Para a preservação do órgão, se utilizou de cardioplegia cristalóide a 4ำ C (SG 5\% $500 \mathrm{ml}+6$ $\mathrm{ml}$ de potássio $19,1 \%+2 \mathrm{ml}$ de bicarbonato de sódio $8,4 \%$ ) no momento da retirada, sendo o órgão acondicionado em recipiente contendo soro fisiológico a $4^{\circ} \mathrm{C}$, e este envolto em sacos estéreis contendo gelo de SF 0,9\%; para o transporte, se utilizou uma bolsa térmica. 
Assef M A S, Valbuena P F M F, Neves Jr. M. T, Correia E B, Vasconcelos M, Manrique R, Magalhães H M, Souza L C B, Chaccur P. Dinkhuysen J J - Transplante cardíaco no Instituto Dante Pazzanese de Cardiologia: análise da sobrevida. Rev Bras Cir Cardiovasc 2001; 16(4): 289-304

\section{GRÁFICO 1 \\ INDICAÇÕES DE TRANSPLANTE CARDÍACO}

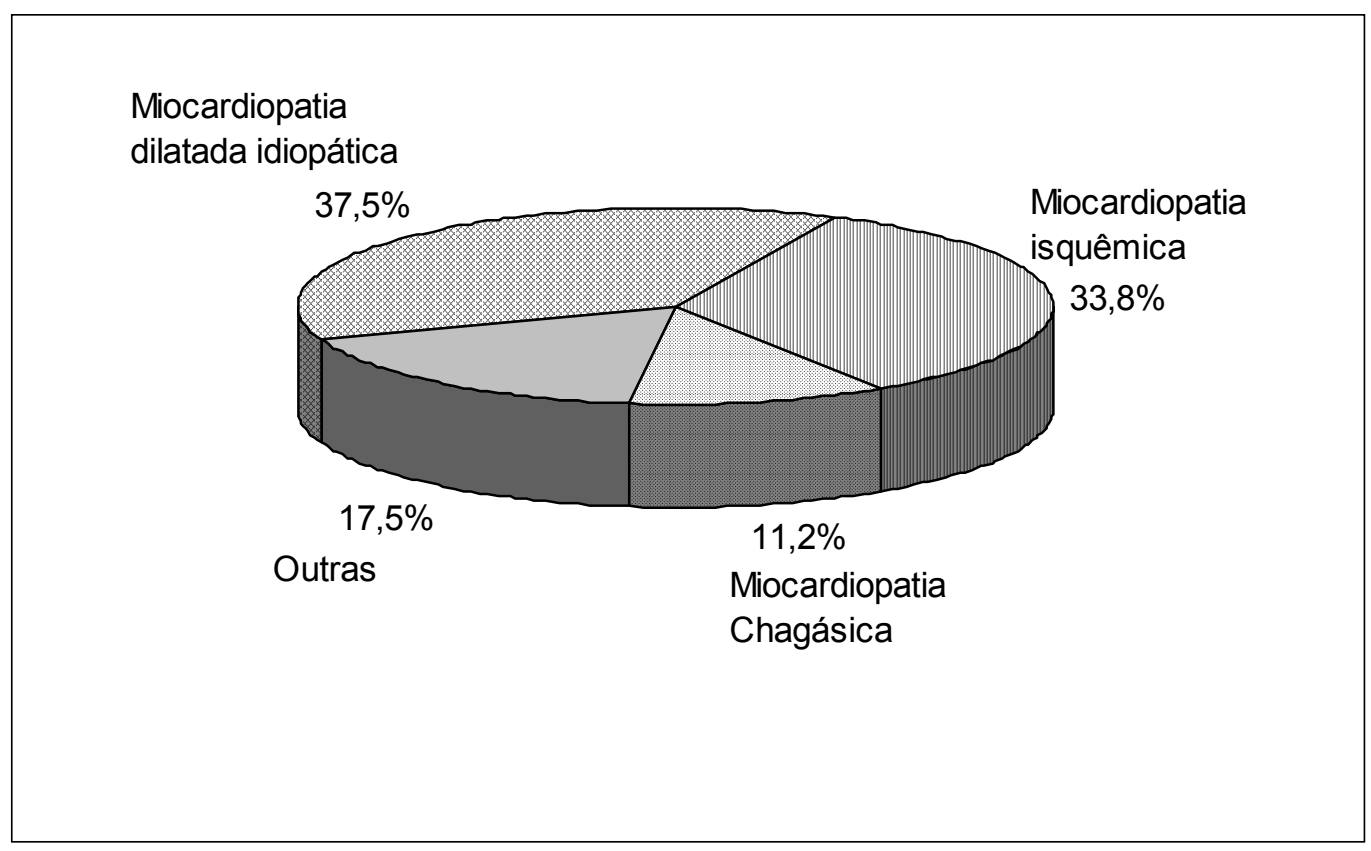

$\mathrm{Na}$ maioria dos casos a retirada do órgão foi realizada em outro hospital $(74 \%)$, dentro da cidade de São Paulo, sendo nos casos mais distantes onde o transporte terrestre pudesse se prolongar, se utilizado do transporte aéreo. Somente $21(26 \%)$ casos foram realizados com doadores que estavam no IDPC.

O tempo médio de isquemia total do órgão oscilou ao redor de 90 minutos quando o transplante foi realizado lado a lado ao local do doador, e de 125 minutos quando houve busca à distância.

O acompanhamento clínico dos 80 casos foi de $100 \%$.

O controle imunológico foi realizado através de biópsias endomiocárdicas, as quais foram realizadas semanalmente no $1^{\circ}$ mês, quinzenalmente do $2^{\circ}$ ao $3^{\circ}$ mês, mensalmente do $4^{\circ}$ ao $6^{\circ}$ mês, bimestralmente do $7^{\circ}$ ao $12^{\circ}$ mês e a partir do primeiro ano, anualmente ou diante da suspeita de rejeição.

O cateterismo cardíaco com cineangiocoronariografia e, mais recentemente, o ultra-som intracoronário têm sido realizados anualmente para o controle da doença coronária do enxerto.

O esquema de imunossupressão utilizado baseou-se no uso de corticoesteróides, ciclosporina e a azatioprina, sendo esta última substituída, em alguns casos, pelo micofenolato de mofetil. Anticorpo antilinfocitário e o FK506 foram usados em alguns casos de rejeição.
Para a análise estatística da sobrevida foi utilizado o Teste do Qui Quadrado para variáveis categóricas, Kaplan-Maier para as curvas de sobrevida e Log-Rank Test para comparação entre curvas. Os dados foram processados pelo programa SPSS / Windows (release 6.0) SPSS Inc. Chigaco IL, 1993.

\section{RESULTADOS}

\section{Sobrevida Geral}

A sobrevida global foi de $70,4 \%$ em um ano, de $59,9 \%$ em cinco anos e de $55,0 \%$ em sete anos (Gráfico 2).

A mortalidade hospitalar (30 dias) foi de 18,75\% (15 casos). A mortalidade tardia também foi de 15 casos ( 8 casos após 30 dias e antes do primeiro ano e 7 casos após o primeiro ano de transplante), perfazendo um total de $30(37,5 \%)$ óbitos.

Quanto à mortalidade hospitalar, houve $3(20 \%)$ casos por acidente vascular encefálico (AVE), 3 (20\%) por baixo débito cardíaco, $2(13,3 \%)$ por rejeição, $2(13,3 \%)$ por sepsis, $2(13,3 \%)$ por coagulopatia, $2(13,3 \%)$ por hipertensão arterial pulmonar (HAP) e $1(6,7 \%)$ caso por morte súbita (Gráfico 3).

A mortalidade tardia ocorrida até um ano de evolução pós-transplante (8 casos) deveu-se à 
Assef M A S, Valbuena P F M F, Neves Jr. M. T, Correia E B, Vasconcelos M, Manrique R, Magalhães H M, Souza L C B, Chaccur P, Dinkhuysen J J - Transplante cardíaco no Instituto Dante Pazzanese de Cardiologia: análise da sobrevida. Rev Bras Cir Cardiovasc 2001; 16(4): 289-304

GRÁFICO 2

CURVA DE SOBREVIDA DE 80 CASOS DE TRANPLANTE CARDÍACO NO INSTITUTO DANTE PAZZANESE DE CARDIOLOGIA

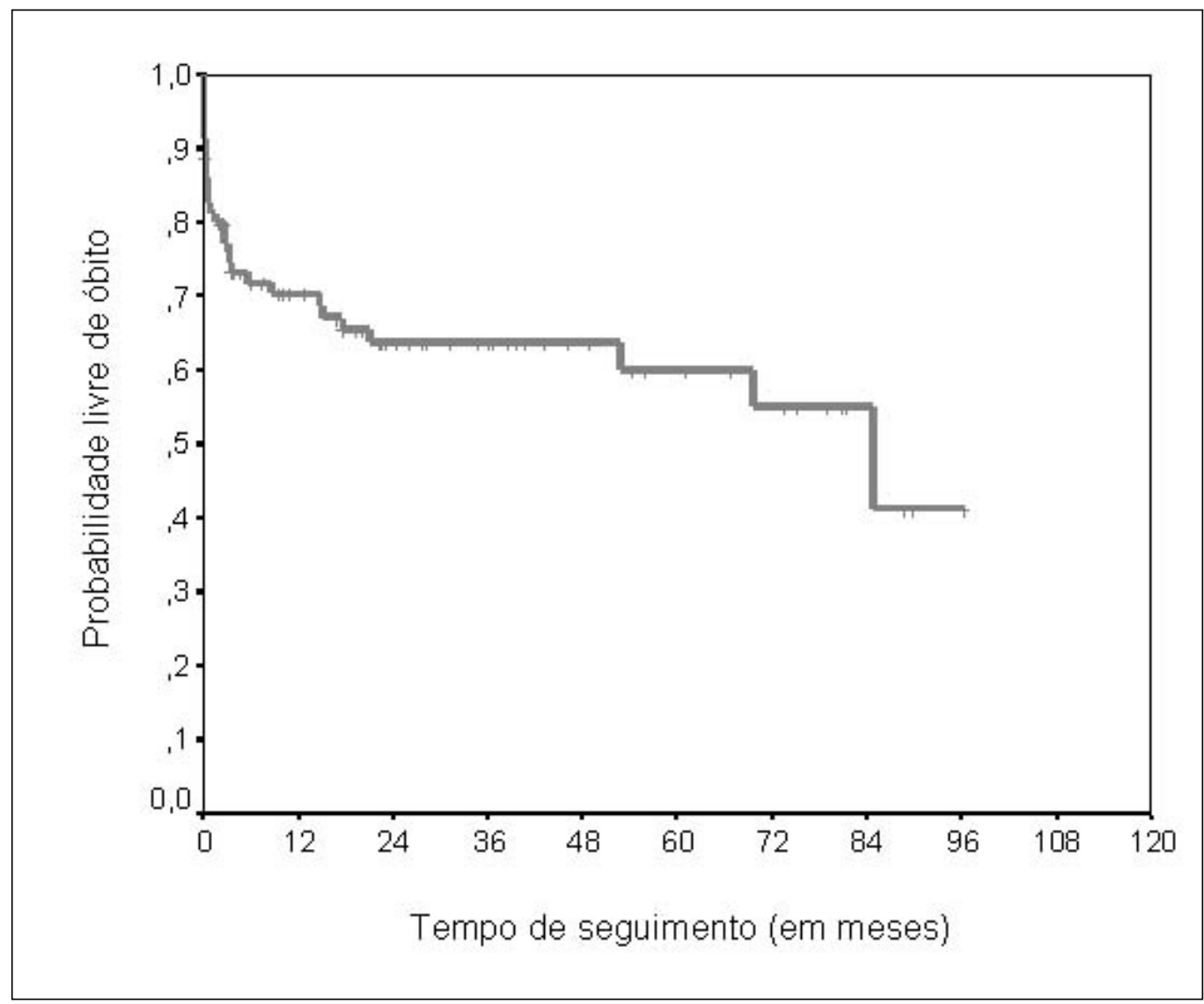

\section{CAUSAS DE ÓBITO HOSPITALAR}

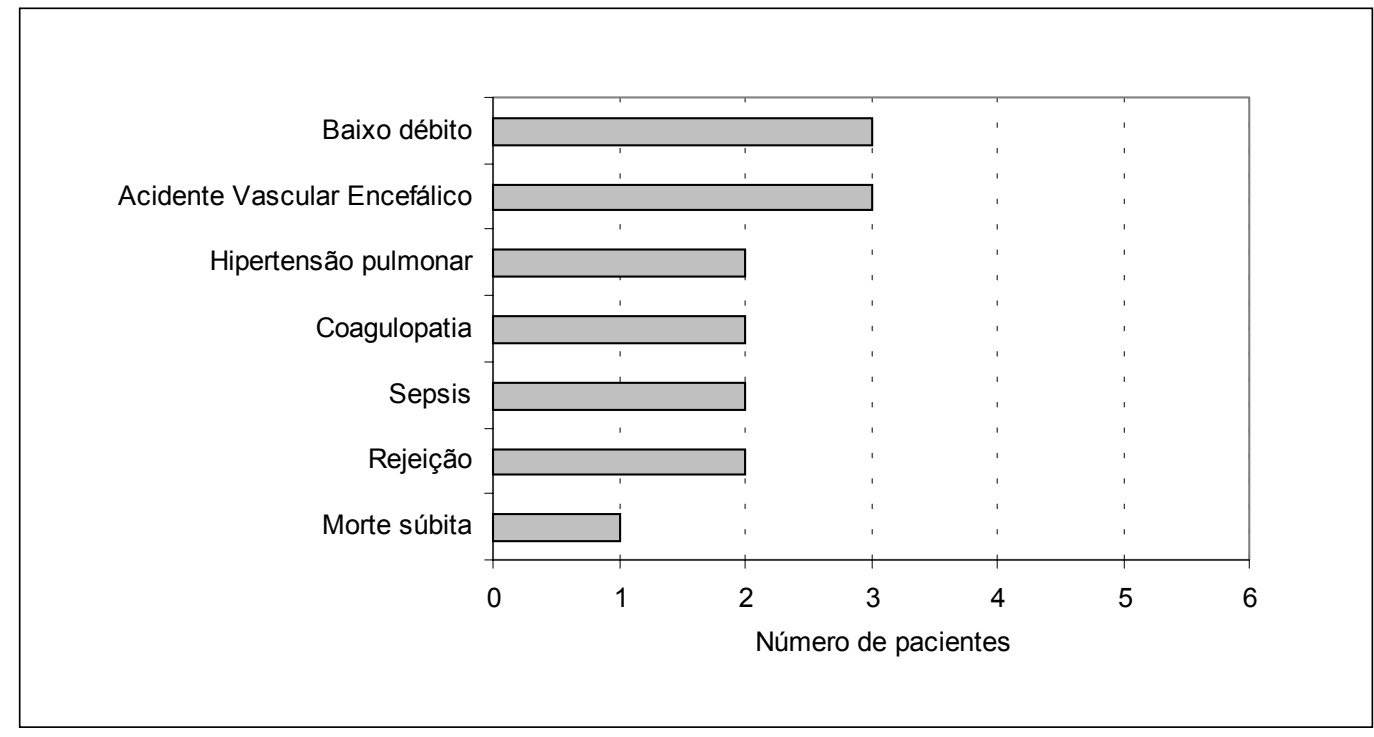


Assef M A S, Valbuena P F M F, Neves Jr. M. T, Correia E B, Vasconcelos M, Manrique R, Magalhães H M, Souza L C B, Chaccur P. Dinkhuysen J J - Transplante cardíaco no Instituto Dante Pazzanese de Cardiologia: análise da sobrevida. Rev Bras Cir Cardiovasc 2001; 16(4): 289-304

sepsis em $2(25,0 \%)$ casos, ao baixo débito cardíaco em $2(25,0 \%)$, ao infarto agudo do miocárdio (IAM) em 1 (12,5\%), à morte súbita em 1 (12,5\%), ao AVE em $1(12,5 \%)$ e à broncopneumonia (Bcp) em $1(12,5 \%)$ caso. Já a mortalidade após um ano deveu-se ao AVE em 2 (28,5\%) casos, ao IAM em $1(14,3 \%)$ caso, ao abandono do tratamento em 1 $(14,3 \%)$ caso, à insuficiência renal aguda (IRA) em $1(14,3 \%)$ caso, à morte súbita em 1 (14,3\%) caso e à reativação de tuberculose ( $\mathrm{Tb})$, com acometimento renal, em 1 (14,3\%) caso, como demonstrado no Gráfico 4.

Sobrevida no $1^{\circ}$ e $5^{\circ}$ Ano Pós-Transplante, Segundo a ldade do Doador

Receptores cujos doadores apresentavam idade inferior a 40 anos tiveram sobrevida em um ano de $79,3 \%$, sendo de $54,0 \%$ no subgrupo com idade maior ou igual a 40 anos. Quanto à sobrevida no quinto ano de pós-operatório (PO), a diferença é estatisticamente maior: $74,2 \%$ e $34,3 \%$, respectivamente, com $\mathrm{p}<0,01$ (Gráfico 5).

Sobrevida no $1^{\circ}$ e 5 Ano Pós-Transplante, Segundo a Causa de Óbito do Doador
Quando o AVE (isquêmico/hemorrágico) foi a causa de morte encefálica do doador, observou-se piora da sobrevida dos receptores para o primeiro e quinto ano de $P O$, sendo de $58,6 \%$ e $46,3 \%$ respectivamente nesse grupo (Gráfico 6) e de $77,8 \%$ e $69,9 \%$ quando a causa foi trauma ou tumor cerebral $(p<0,05)$.

\section{Sobrevida no $1^{\circ}$ e $5^{\circ}$ Ano Pós-Transplante, Segundo} o Sexo do Doador

Não houve significância estatística na sobrevida em 1 e 5 anos dos receptores quando se comparou os doadores quanto ao sexo $(p>0,05)$.

Sobrevida no $1^{\circ}$ e $5^{\circ}$ Ano Pós-Transplante, Segundo o Sexo do Doador X Idade do Doador

A análise de doadores do sexo masculino $x$ idade não foi estatisticamente significante nessa casuística $(p>0,05)$. Entretanto, no grupo das muIheres doadoras com idade menor de 40 anos a sobrevida dos receptores em um ano foi de $88,9 \%$, mantendo esse mesmo nível até o quinto ano de $\mathrm{PO}$, enquanto que no das mulheres doadoras com 40 anos ou mais a sobrevida foi de $40,6 \%$ no primeiro ano e $16,3 \%$ no quinto ano de $P O(p<0.01)$, como se observa no Gráfico 7.

GRÁFICO 4

MORTALIDADE TARDIA SEGUNDO CAUSAS DE ÓBITO

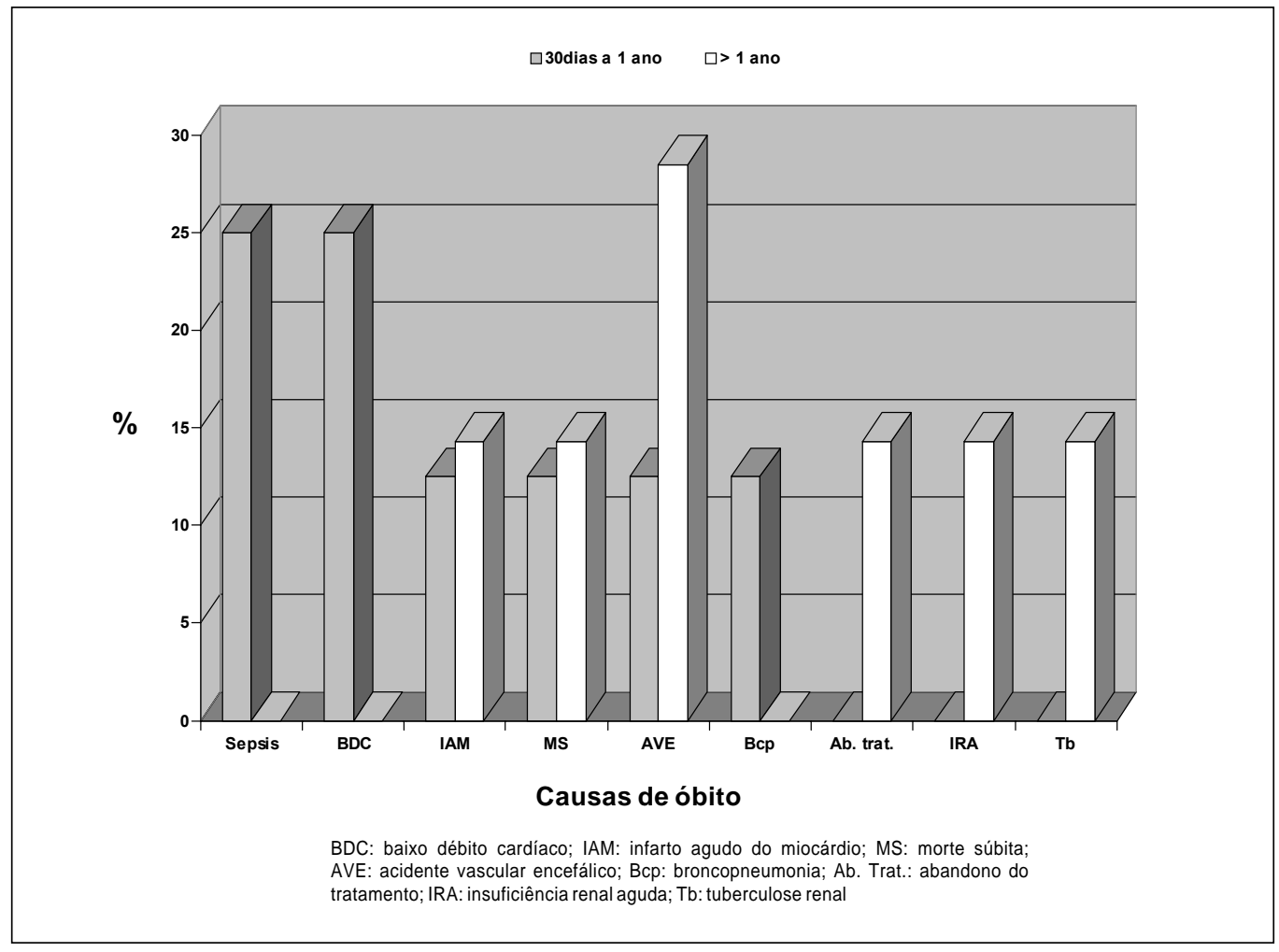


Assef M A S, Valbuena P F M F, Neves Jr. M. T, Correia E B, Vasconcelos M, Manrique R, Magalhães H M, Souza L C B, Chaccur P, Dinkhuysen J J - Transplante cardíaco no Instituto Dante Pazzanese de Cardiologia: análise da sobrevida. Rev Bras Cir Cardiovasc 2001; 16(4): 289-304

GRÁFICO 5

SOBREVIDA SEGUNDO A IDADE DO DOADOR

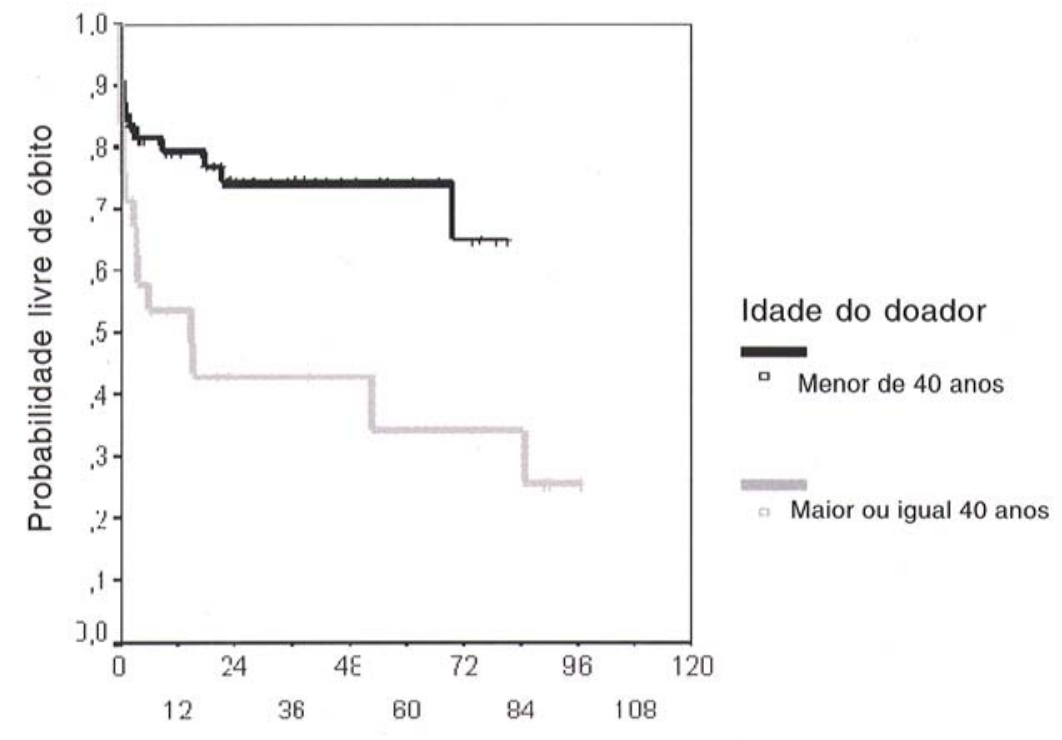

Tempo de seguimento (em meses)

GRÁFICO 6

SOBREVIDA SEGUNDO A CAUSA DE ÓBITO DO DOADOR

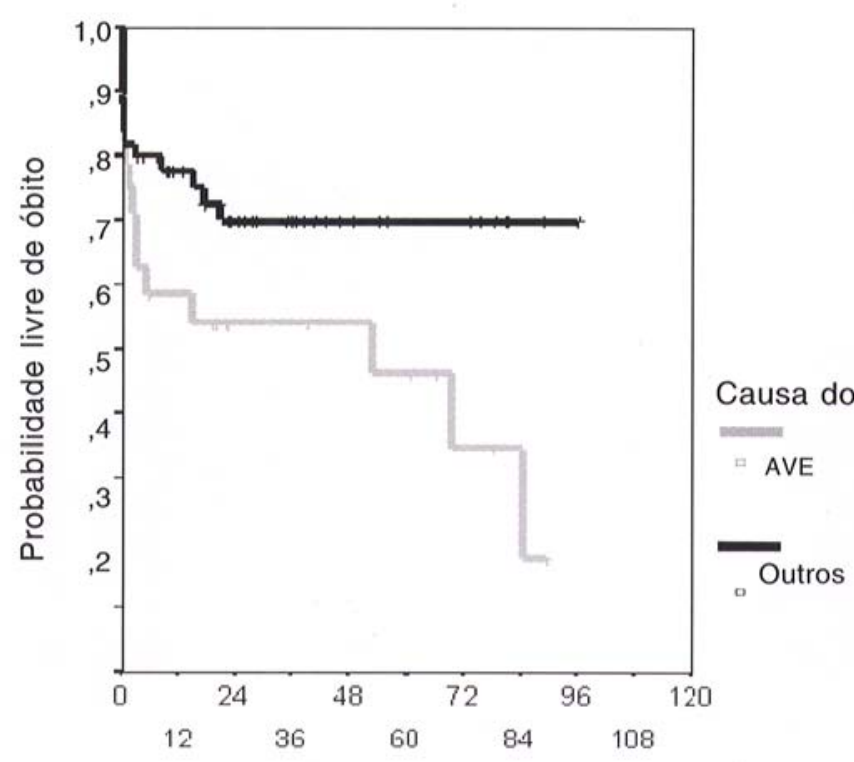

Tempo de seguimento (em meses) 
Assef M A S, Valbuena P F M F, Neves Jr. M. T, Correia E B, Vasconcelos M, Manrique R, Magalhães H M, Souza L C B, Chaccur P. Dinkhuysen J J - Transplante cardíaco no Instituto Dante Pazzanese de Cardiologia: análise da sobrevida. Rev Bras Cir Cardiovasc 2001; 16(4): 289-304

\section{GRÁFICO 7 \\ SOBREVIDA COM DOADOR FEMININO SEGUNDO IDADE DO DOADOR}

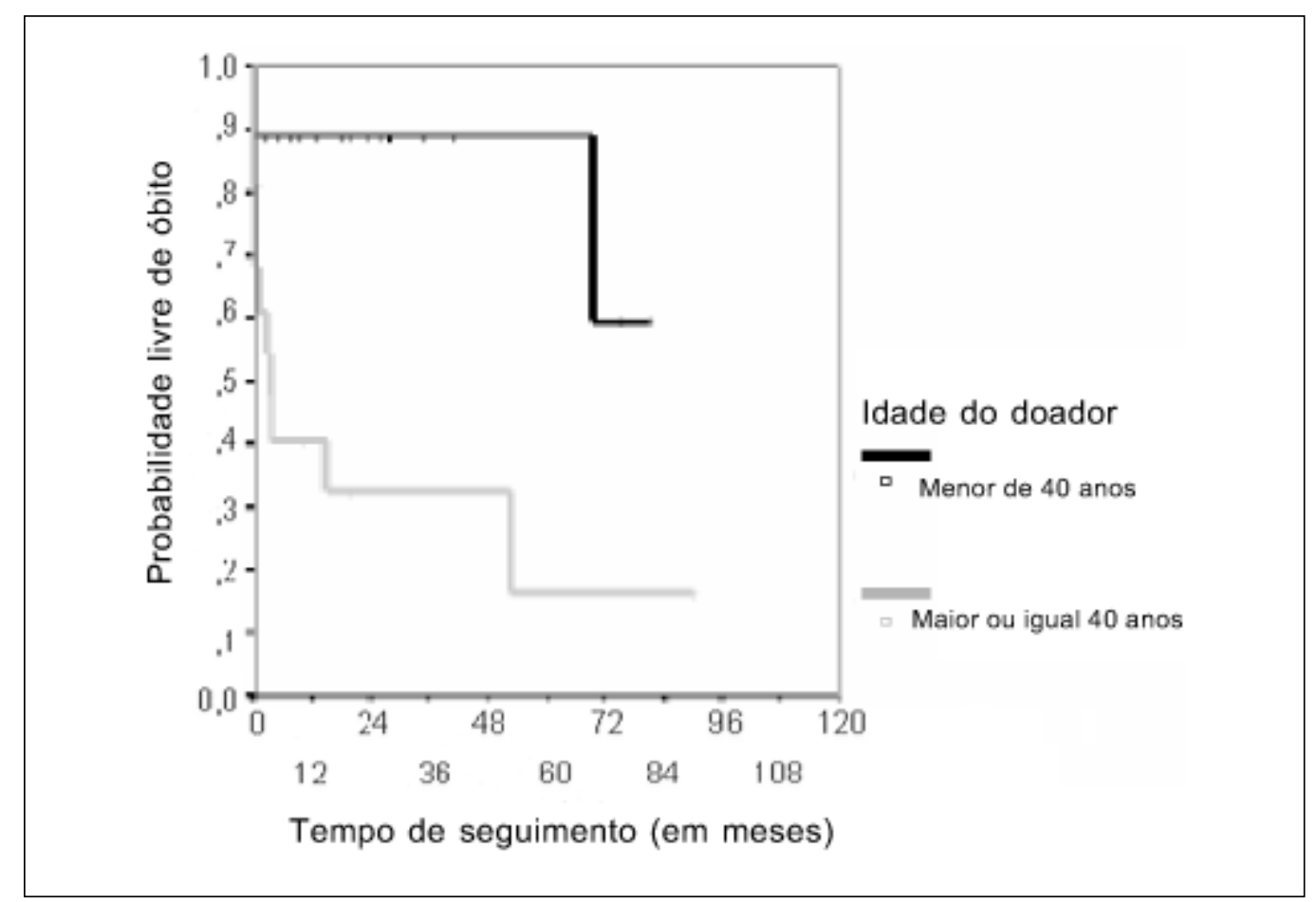

Sobrevida no $1^{\circ}$ e $5^{\circ}$ Ano Pós-Transplante, Segundo o Sexo do Doador X Causa de Óbito do Doador

A sobrevida do receptor cujo doador era do sexo feminino e teve morte encefálica por outra causa que não AVE foi estatisticamente superior quando comparada com o AVE, independente da idade. Nestes, a sobrevida em um e cinco anos foi $87,5 \%$, contra $45,8 \%$ e $26,2 \%$, respectivamente, para o AVE (Gráfico 8), com $p<0,01$. O mesmo fato não se verifica quando o doador pertence ao grupo do sexo masculino (também independente da idade), segundo a causa da morte encefálica $(p>0,05)$.

Sobrevida no $1^{\circ}$ e 5ํ Ano Pós-Transplante, Segundo a Idade do Doador X Causa de Óbito do Doador

A sobrevida do recep'tor cujo doador apresentava menos de 40 anos e teve morte encefálica por outra causa que não AVE não foi estatisticamente superior quando comparada com o AVE, independentemente do sexo. Entretanto, no grupo dos doadores com idade de 40 anos ou mais e que tiveram morte encefálica por outra causa que não $A V E$, a sobrevida dos receptores em um ano foi de $89 \%$, mantendo este mesmo índice aos cinco anos, enquanto que naqueles com AVE $46,1 \%$ e $26,3 \%$, respectivamente, com $p<0,05$ (Gráfico 9).

Sobrevida no $1^{\circ}$ e $5^{\circ}$ Ano Pós-Transplante, Segundo a Prioridade do Receptor

$\mathrm{Na}$ casuística do IDPC $15 \%$ dos receptores estavam em prioridade para transplante. A sobrevida não foi distinta daquele que aguarda aleatoriamente 0 transplante $(p>0,05)$.

Sobrevida no 1ํ e 5 Ano Pós-Transplante, Segundo a Reoperação

Cirurgia cardíaca prévia (uma ou mais) foi observada em $25 \%$ dos nossos receptores, tendo esse antecedente afetado a sobrevida, que em um e cinco anos de PO foi de $53,3 \%$ e $42,0 \%$ respectivamente, enquanto nos não reoperados foi de $76,0 \%$ e $66,6 \%$, com $p<0,05$ (Gráfico 10).

Sobrevida no $1^{\circ}$ e 5ํAno Pós-Transplante, Segundo a Diabete Mellitus

O diagnóstico prévio de DM não insulino-dependente, encontrado em $10 \%$ dos nossos receptores, não modificou a sobrevida em um e cinco anos quando comparada com o restante do grupo $(p>0,05)$. 
Assef M A S, Valbuena P F M F, Neves Jr. M. T, Correia E B, Vasconcelos M, Manrique R, Magalhães H M, Souza L C B, Chaccur P, Dinkhuysen J J - Transplante cardíaco no Instituto Dante Pazzanese de Cardiologia: análise da sobrevida. Rev Bras Cir Cardiovasc 2001; 16(4): 289-304

GRÁFICO 8

SOBREVIDA COM DOADOR FEMININO SEGUNDO CAUSA DE ÓBITO DO DOADOR

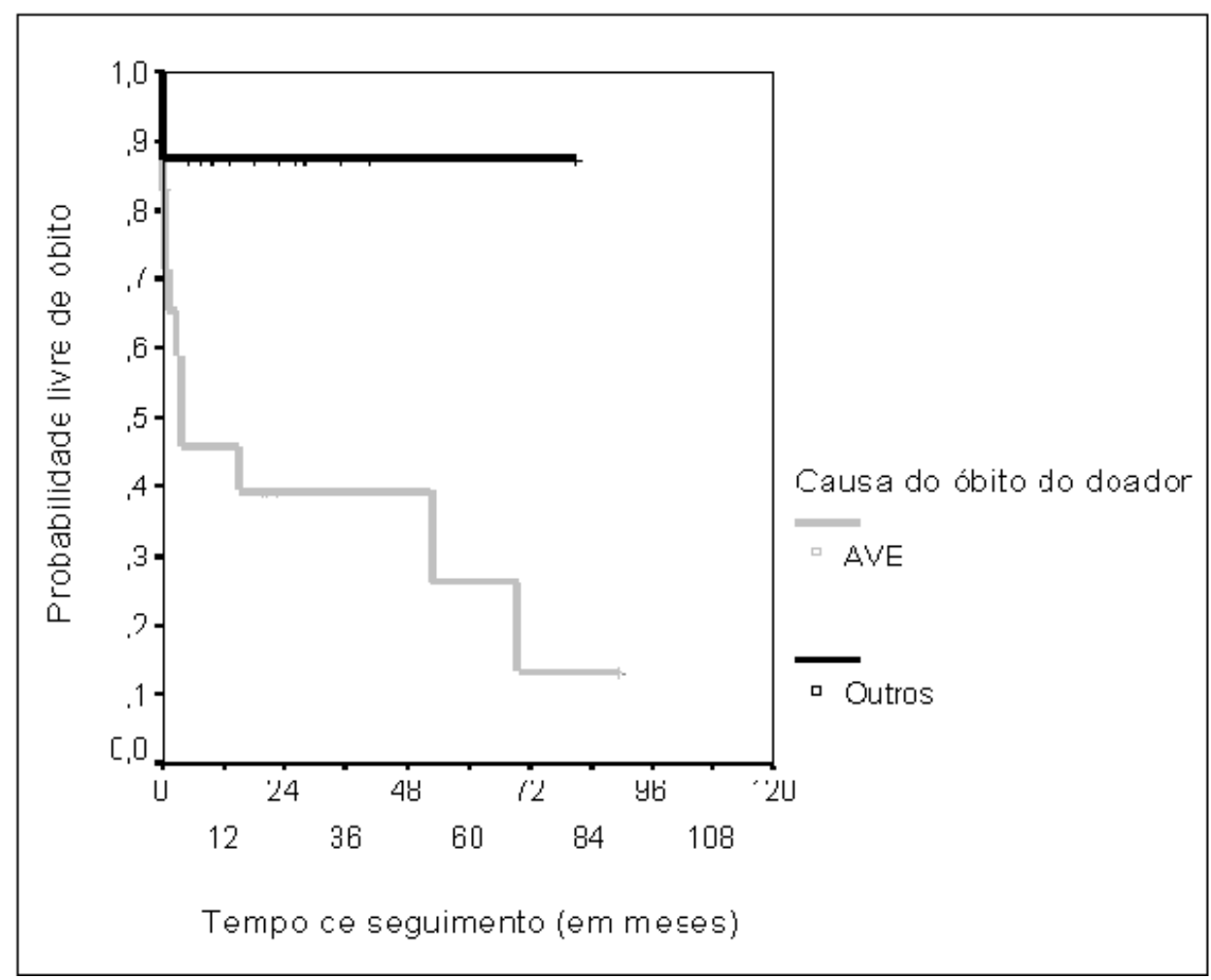

GRÁFICO 9

SOBREVIDA QUANDO O DOADOR SOFREU AVE SEGUNDO FAIXA ETÁRIA

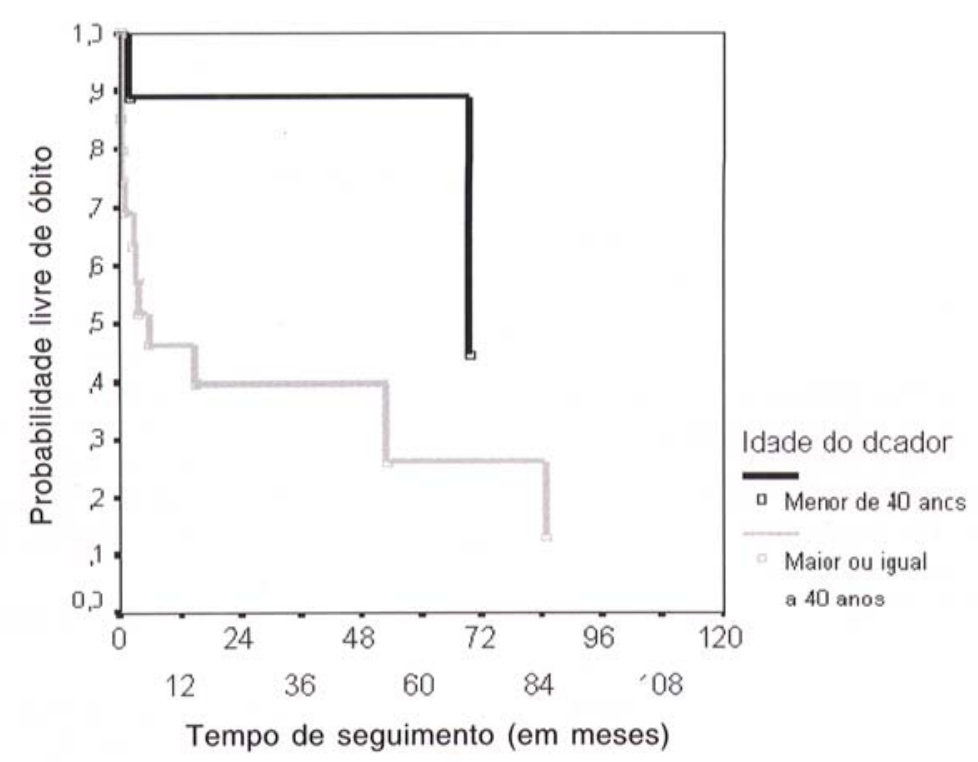


Assef M A S, Valbuena P F M F, Neves Jr. M. T, Correia E B, Vasconcelos M, Manrique R, Magalhães H M, Souza L C B, Chaccur P. Dinkhuysen J J - Transplante cardíaco no Instituto Dante Pazzanese de Cardiologia: análise da sobrevida. Rev Bras Cir Cardiovasc 2001; 16(4): 289-304

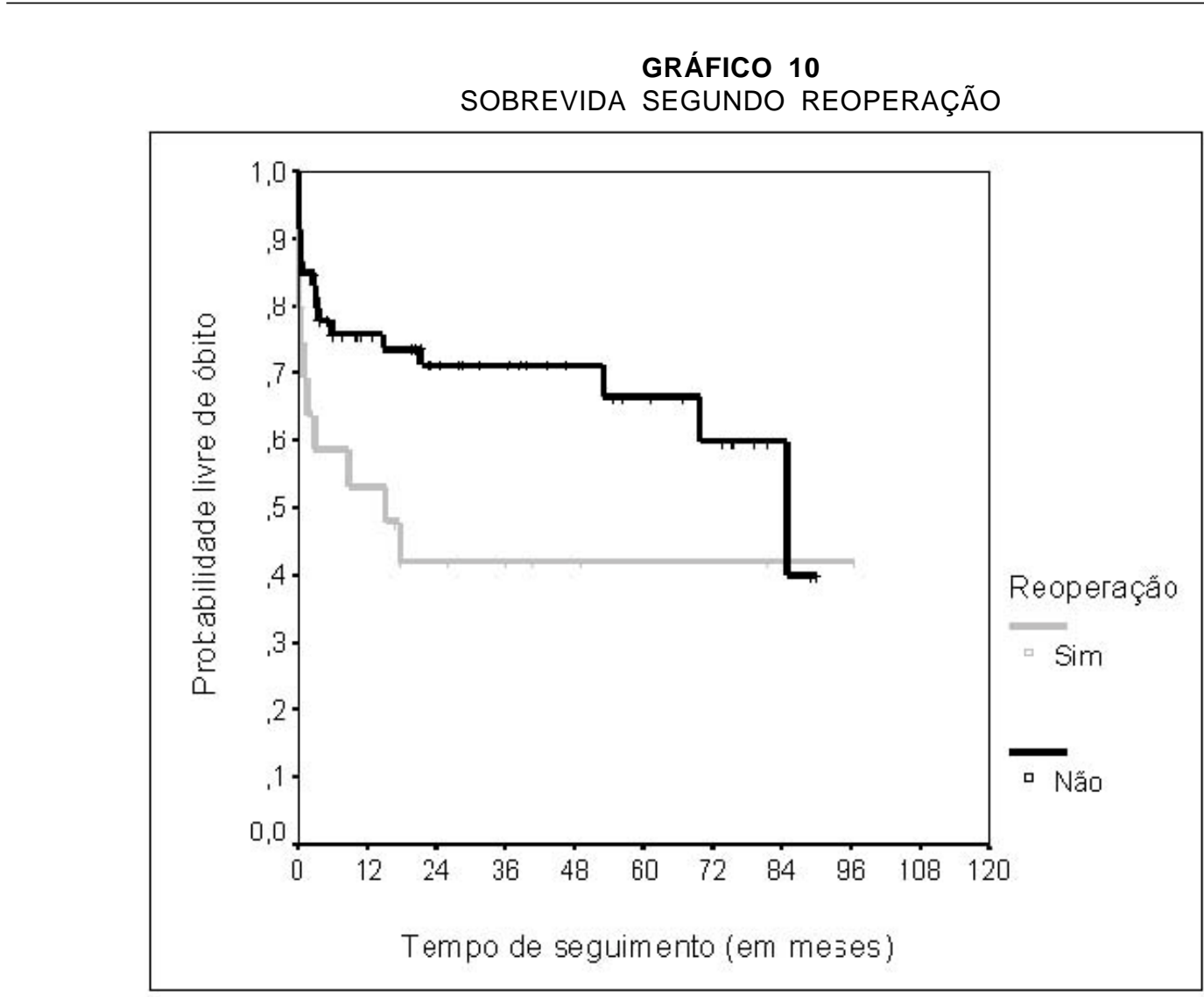

Sobrevida no $1^{\circ}$ e $5^{\circ}$ Ano Pós-Transplante, Segundo a Técnica Cirúrgica

A análise estatística de sobrevida para $01^{\circ} \mathrm{e}$ $5^{\circ}$ ano pós-transplante não mostrou diferenças significativas $(p>0,05)$ quando foi utilizada a técnica bicaval/bipulmonar (51 casos) ou técnica atrial (22 casos).

Sobrevida no $1^{\circ}$ e $5^{\circ}$ Ano Pós-Transplante, Segundo a Etiologia da ICC

A etiologia determinante da ICC foi MDI em $37,5 \%$ dos receptores, $\mathrm{Ml}$ em $33,8 \%$, MC em $17,5 \%$ e outras causas em $11,2 \%$, e não apresentou significância estatística na sobrevida $(p>0,05)$.

\section{Sobrevida no $1^{\circ}$ e $5^{\circ}$ Ano Pós-Transplante, Segundo} a Reativação de Chagas

Reativação do quadro de Chagas nos portadores desta doença não modificou a sobrevida $(p>0,05)$. Em $17,5 \%$ dos receptores a ICC era secundária a miocardiopatia chagásica. A reagudização ocorreu em $28,6 \%$ destes transplantados. Verificou-se reativação no caso do retransplante no primeiro e no segundo coração implantado.

Sobrevida no $1^{\circ}$ e $5^{\circ}$ ano Pós-Transplante, Segundo a Faixa Etária do Receptor

Analisou-se a sobrevida dos receptores em relação à idade, conforme esta ser menor de 50 anos ou igual ou maior de 50 anos. Não houve significância estatística na sobrevida $(p>0,05)$.

Sobrevida no $1^{\circ}$ e $5^{\circ}$ Ano Pós-Transplante, Segundo o Sexo do Receptor

Não houve significância estatística na sobrevida quando se comparou os receptores quanto ao sexo $(p>0,05)$.

\section{COMENTÁRIOS}

Atualmente, não há dúvida em se afirmar que o transplante cardíaco ortotópico é modalidade terapêutica consagrada, com resultados favoráveis a curto e a longo prazos. 
Assef M A S, Valbuena P F M F, Neves Jr. M. T, Correia E B, Vasconcelos M, Manrique R, Magalhães H M, Souza L C B, Chaccur P, Dinkhuysen J J - Transplante cardíaco no Instituto Dante Pazzanese de Cardiologia: análise da sobrevida. Rev Bras Cir Cardiovasc 2001; 16(4): 289-304

$\mathrm{Na}$ grande maioria das vezes, os candidatos ao transplante já se encontram deteriorados em todos os aspectos: a ICC terminal levando à repercussões sistêmicas; o perfil psicológico do paciente e de sua família é precário, pois todas as condições de estabilização psicológica se esgotaram, seus recursos econômicos, muitas vezes, já foram consumidos em tratamentos anteriores prolongados, associado, na maioria das vezes, ao abandono do trabalho.

Por estas razões, entendemos que uma equipe multidisciplinar (incluindo clínicos, cirurgiões, psicólogos, enfermeiros, assistentes sociais, fisioterapeutas e nutricionistas) em uma instituição hospitalar preparada deva ser estruturada, para que se consiga oferecer não só resultados satisfatórios a curto prazo, mas também curvas atuariais de sobrevida e qualidade de vida a longo prazo bastante consistentes, dando cada vez mais credibilidade, principalmente em nosso meio, ao transplante cardíaco como opção terapêutica da ICC grave.

O prognóstico do transplante cardíaco pode ser correlacionado a uma série de variáveis, e o volume de informações disponível a respeito de cada uma dessas é grande; diante disto procuramos correlacionar variáveis pertinentes ao doador e ao receptor no que tange em uma maior sobrevida a curto e a longo prazos.

Como ocorre em outras casuísticas nacionais e internacionais $(7,10)$, a maioria dos pacientes é do sexo masculino, em mais de $60 \%$ dos casos. Comparando a curva de sobrevida em 1 e 5 anos entre os sexos, não foram observadas diferenças estatisticamente significativas, embora haja relatos que preconizam uma menor sobrevida a longo prazo quando o receptor é do sexo feminino (7), principalmente se a paciente for multípara, pela maior incidência de eventos de rejeição (11)

No que se refere à idade do receptor, costuma predominar a faixa etária entre os 35 e 60 anos $(7,10)$. Nesta casuística, $61(76,2 \%)$ pacientes se encontravam nesta faixa, e a idade média foi de 44,8 anos. Comparando-se a sobrevida dos receptores em relação a ter menos de 50 anos ou mais, não houve diferenças estatisticamente significativas para 1 e 5 anos, mostrando que a idade isoladamente, quando considerada dentro destes dois grupos etários, não foi fator de mal prognóstico neste estudo, como também em outro que considerou somente pacientes com mais de 60 anos (12). Entretanto, o registro da International Society for Heart and Lung Transplantation de 1999 (7) mostrou que receptores acima de 50 anos começam a apresentar pior sobrevida logo no $1^{\circ}$ ano de pós-transplante, persistindo também aos cinco anos. Também para aqueles com idade superior a 65 anos a mortalidade chega a ser $50 \%$ maior, provavelmente pela maior probabilidade destes pacientes desenvolverem doenças relacionadas à idade mais avançada, como hipertrofia prostática, osteoporose e doença aterosclerótica, situando-se como mais propensos a complicações (13).

Analisando-se a curva de sobrevida no que se refere à etiologia da ICC, não se observou diferença estatisticamente significativa para 1 e 5 anos, embora o registro da International Society for Heart and Lung Transplantation de 1999 (7) mostre pior prognóstico quando a causa da ICC for outra diferente de $\mathrm{MI}$ ou MDI. Dos casos de receptores chagásicos desta casuística (17,5\%), em 4 (28,6\%) houve episódios de reativação da doença no enxerto, sem nenhum óbito, sendo que em uma mesma paciente tanto no $1^{\circ}$ como no $2^{\circ}$ transplante. Tal reativação foi a causa da falência do órgão na primeira operação, sendo realizado o retransplante exatamente dois meses após o primeiro implante e, mesmo assim, a seguir a paciente voltou a apresentar reativação do Chagas, mas aí o tratamento clínico com benzonidazol obteve sucesso. Relato semelhante pode ser observado na casuística da Universidade Federal de São Paulo (10), onde $33,3 \%$ dos chagásicos tiveram reativação da doença de Chagas e apresentaram resposta favorável com o tratamento clínico apropriado.

Nesta casuística, 50 pacientes se encontravam em classe funcional III da NYHA e 30 em classe IV (sendo 12 em prioridade para transplante, internados em uso de drogas inotrópicas endovenosas). Estudo realizado em nosso meio (14) mostrou que a mortalidade no final do segundo ano é de $75 \%$ para pacientes em classe IV e de $50 \%$ no final do terceiro ano para pacientes em classe III, subindo para $75 \%$ no final do primeiro ano para pacientes internados em uso de drogas inotrópicas endovenosas e/ou suporte circulatório mecânico.

Sabendo-se que a classe funcional avançada é uma situação praticamente definitiva e não um estado transitório e reversível, que a medicação esteja otimizada e já tenha sido necessária a internação hospitalar, o transplante cardíaco deve ser indicado, principalmente nos casos com consumo máximo de oxigênio menor que $10 \mathrm{ml} / \mathrm{K} / \mathrm{min}$ pois costumam apresentar pior prognóstico a curto e a médio prazo ${ }^{(15,16)}$. Já nos casos com ICC em classe I e II, a mortalidade em um ano fica comparável aos pacientes submetidos ao transplante, que é ao redor de $20 \%$ (17).

Dos pacientes colocados em prioridade, com instabilidade clínica e descompensação da ICC, em uso de drogas inotrópicas endovenosas, não se obteve diferença estatisticamente significativa na sobrevida a curto e a longo prazo quando 
Assef M A S, Valbuena P F M F, Neves Jr. M. T, Correia E B, Vasconcelos M, Manrique R, Magalhães H M, Souza L C B, Chaccur $P$, Dinkhuysen J J - Transplante cardíaco no Instituto Dante Pazzanese de Cardiologia: análise da sobrevida. Rev Bras Cir Cardiovasc 2001; 16(4): 289-304

analisado este fato isoladamente, embora nenhum deles estivesse em uso de dispositivos de assistência circulatória. Sabe-se que a mortalidade nos primeiros seis meses é bem maior neste grupo, onde também se observa níveis séricos elevados de creatinina e transaminases, embora não haja diferença significativa na sobrevida para aqueles que superam este período inicial $(5,18)$. Neste estudo, alguns se encontravam em disfunção hepato-renal transitória devido à descompensação da ICC, mas nenhum com dano orgânico estabelecido.

Os pacientes previamente operados do coração (20 casos) por uma ou mais vezes (até 5 vezes) apresentaram uma sobrevida estatisticamente inferior ao grupo de não operados. Dos 20 casos, 11 faleceram, sendo 6 no primeiro mês, e nestes prevaleceu o AVE e os distúrbios de coagulação como principais causas, provavelmente correlacionados a um maior tempo de circulação extracorpórea e ao maior sangramento que as reoperações proporcionam. No caso do retransplante, houve necessidade de se canular a veia femoral direita por dificuldade em se expor a cava inferior (técnica bicaval), e apesar da maior mortalidade nestes casos, principalmente quando o retransplante é realizado em menos de 2 anos do primeiro ${ }^{(7)}$, esta paciente evolui favoravelmente.

A captação do coração geralmente foi feita em outro Serviço (76\% das vezes), como na maioria dos Serviços americanos $(19,20)$, mas diferente da casuística nacional $(10,21)$. Entretanto, apesar do tempo total de isquemia do órgão ser maior nestes casos, ele foi em média de 125 minutos, nunca ultrapassando quatro horas, tempo hábil e bem tolerado, conforme relatos da literatura $(7,22)$.

Dos 8 pacientes portadores de DM não insulinodependente, apenas um evoluiu com resistência ao tratamento com hipoglicemiante oral após o transplante, necessitando usar insulina; mesmo não fazendo uso de corticoesteróides para evitar descompensação da diabete, já apresenta complicações da DM avançada (impotência sexual e neuropatia periférica). A análise estatística não mostrou diferença na sobrevida deste grupo em relação aos não diabéticos, tanto para um quanto para cinco anos de $\mathrm{PO}$.

A partir de fevereiro de 1996 foi introduzida no Serviço modificação na técnica prescrita por LOWER \& SHUMWAY (2) (técnica biatrial ou clássica), passando-se a se utilizar a técnica bicaval e unipulmonar, conforme idealizada experimentalmente por WEBB et al. (23) e CASS \& BROCK ${ }^{(24)}$, em 1959, (e utilizada posteriormente por YACOUB et al. (25) e por DREYFUS et al. (26) ) em 5 casos consecutivos. Logo depois nova modificação técnica foi introduzida, deixando-se somente as veias pulmonares do receptor(técnica bicaval/bipulmonar), conforme preconizado por estes e outros autores (25-28). Desde então, 51 casos foram realizados por este método.

A análise estatística da sobrevida, quando comparados os dois maiores grupos de pacientes conforme a técnica ser a atrial (22 casos) ou bicaval/ bipulmonar (51 casos) não mostrou diferenças na sobrevida de um ou cinco anos. Entretanto, como demonstrado anteriormente em trabalho desta Instituição (29) e em outros relatos (30-32), na técnica bicaval é menor a incidência de taquiarritmias e o uso de marcapasso definitivo, bem como é menor o índice de regurgitação mitral ou tricúspide $(25,33)$. $\mathrm{Na}$ nossa casuística, não temos nenhum paciente que necessitou de marcapasso definitivo após a técnica bicaval/bipulmonar, enquanto que há um após a técnica atrial. Sabe-se, também, que a função e o transporte atrial esquerdo são significativamente inferiores pela técnica atrial [como também pôde ser observado num estudo ecocardiográfico com Doppler realizado nesta Instituição, que mostrou melhor função contrátil do átrio esquerdo, bem como maior fração de enchimento $(p<0,05){ }^{(34)}$.

Dois pacientes foram submetidos ao transplante, heterotópico por apresentarem resistência pulmonar entre 5 e $8 U$ Wood, pouco responsivos ao teste com vasodilatador (nitroprussiato de sódio); o primeiro deles chegou a ter alta hospitalar, mas faleceu um mês e meio após por mediastinite, confirmada em necropsia, e o segundo faleceu no PO imediato, por baixo débito cardíaco. Isto reforça a idéia que esta técnica deva ser restrita a casos selecionados de hipertensão pulmonar, já que sua mortalidade é bem superior ao transplante ortotópico (35).

Em relação aos doadores, procurou-se selecionar aqueles com estabilidade hemodinâmica em uso de no máximo $10 \mathrm{mcg} / \mathrm{K} / \mathrm{min}$ de dopamina, com volemia compensada, sem septicemia, peso compatível ao receptor, compatibilidade sanguínea do grupo $A B 0$, sorologias negativas para HIV 1 e 2 , sífilis, hepatites B e C e Chagas; positividade para citomegalovírus e toxoplasmose fazem com que o receptor seja prontamente tratado após o transplante, não sendo contra-indicação absoluta para o procedimento. Procurou-se evitar doadores cuja logística induza tempo de isquemia total do enxerto superior a quatro horas.

O registro da International Society for Heart and Lung Transplantation de 1999 (7) mostrou que a maioria dos doadores de coração na última década tinha entre 25 e 30 anos. Entretanto, em nosso meio, a obtenção de potenciais doadores é deficitária por uma série de razões, desde o desinteresse por parte dos médicos intensivistas em cuidar de um paciente com morte encefálica, falhas 
Assef M A S, Valbuena P F M F, Neves Jr. M. T, Correia E B, Vasconcelos M, Manrique R, Magalhães H M, Souza L C B, Chaccur P, Dinkhuysen J J - Transplante cardíaco no Instituto Dante Pazzanese de Cardiologia: análise da sobrevida. Rev Bras Cir Cardiovasc 2001; 16(4): 289-304

no diagnóstico da morte encefálica, atraso na notificação à Central de Procura de Órgãos (notificação obrigatória) e deficiência em campanhas para a doação de órgãos. Em vista disso, doadores em faixa etária mais elevada estão sendo utilizados no nosso Serviço.

Com a finalidade de analisar a influência da idade nos resultados, dividiu-se os doadores segundo duas faixas etárias: acima e abaixo de 40 anos. Observamos que no subgrupo com idade inferior a 40 anos a sobrevida dos receptores em um ano foi de $79,3 \%$ e naquele com idade maior ou igual a 40 anos foi de $54,0 \%$. Quando analisamos a sobrevida no quinto ano a diferença é ainda maior: $74,2 \%$ e $34,3 \%$, respectivamente $(p<0,01)$, coincidindo com outros relatos $(7,22)$.

Analisando-se os doadores quanto ao fator sexo, isoladamente, como também quando foram analisados só os homens $x$ idade (menores de 40 anos e 40 ou mais) não encontramos diferenças estatisticamente significantes na sobrevida dos receptores nessa casuística ( $p>0,05)$, embora grandes relatos internacionais mostrem o doador do sexo feminino como fator de risco para um pior prognóstico, devido ao fato da maior prevalência de rejeição ${ }^{(5,36)}$. Entretanto, no grupo das mulheres doadoras com idade menor de 40 anos a sobrevida dos receptores em um ano foi de $88,9 \%$, mantendo esse mesmo nível até o quinto ano, enquanto que no das mulheres doadoras com 40 anos ou mais a sobrevida foi de $40,6 \%$ no primeiro ano e de $16,3 \%$ no quinto ano $(p<0.01)$. Isto reforça o achado anterior, salientando também que mulheres doadoras acima de 40 anos predispõem a menor sobrevida do receptor a curto e a longo prazos.

Considerando-se a causa de óbito do doador, quando esta foi por AVE (isquêmico/hemorrágico), observou-se piora na sobrevida dos receptores para o primeiro e quinto ano, sendo de $58,6 \%$ e $46,3 \%$ respectivamente nesse grupo e de $77,8 \%$ e $69,9 \%$ quando o evento morte encefálica estava relacionado à outras causas $(p<0,05)$. Isto se deve provavelmente ao fato desses doadores apresentarem hipertensão arterial de longa data, já com um certo grau de alteração vascular difusa e de hipertrofia ventricular. Entretanto, não foi possível correlacionar tais suspeitas com as respectivas causas de óbito dos receptores que faleceram no primeiro ano, contudo esta associação parece ocorrer quando foram analisados os óbitos tardios.

A sobrevida do receptor cujo doador, independente da idade, era mulher e teve morte encefálica por outra causa que não AVE foi melhor quando comparada com o AVE. Isto também se verificou quando analisados os receptores quanto à idade e causa de morte encefálica. No grupo de doadores do sexo feminino cujo causa da morte encefálica foi AVE a sobrevida dos receptores em um ano foi de $45,8 \%$ e em cinco anos de $26,2 \%$, contra $87,5 \%$ e $87,5 \%$ respectivamente para causas diferentes de AVE $(p<0,01)$; no grupo de doadores com mais de 40 anos cuja causa da morte encefálica foi AVE a sobrevida dos receptores em um ano foi de $46,1 \%$ e em cinco anos de $26,3 \%$, contra $89 \%$ para um e cinco anos, respectivamente, para causas diferentes de AVE $(p<0,05)$. O mesmo fato, ou seja, a melhora da sobrevida nos receptores em um e cinco anos não se verifica quando o doador pertence ao grupo de homens (independentemente da idade), segundo a causa da morte encefálica, bem como para aqueles com menos de 40 anos, segundo a causa da morte encefálica (independentemente do sexo) ( $p>0,05)$.

Isto faz pressupor que o doador do sexo feminino com AVE predispõe a uma menor sobrevida a curto e a longo prazo no receptor, sendo pior quando apresenta mais de 40 anos. Dos 30 pacientes que faleceram, 11 receberam corações provenientes de doadores com estas três características.

A sobrevida dos pacientes após transplante cardíaco no IDPC foi de $70,4 \%$ em um ano, de $59,9 \%$ em cinco anos e de $55,0 \%$ em sete anos. Entretanto, se excluirmos os dois casos de transplante heterotópico, a sobrevida nestes períodos se eleva para $72,7 \%, 61,5 \%$ e $56,4 \%$, respectivamente. Tal resultado é semelhante às estatísticas encontradas em nosso meio $(10,21)$.

Em relação a centros internacionais, o grupo de Stanford (37) mostrou sobrevida de $82 \%$ e $61 \%$ para 1 e 5 anos, enquanto que o registro da International Society for Heart and Lung Transplantation de 1999 (7) $79 \%$ para o $1^{\circ}$ ano e $63,6 \%$ para o $5^{\circ}$ ano, sendo que $50 \%$ dos pacientes estavam vivos por volta de 8,8 anos de segmento.

A mortalidade hospitalar (até 30 dias) foi de $18,75 \%$ (15 casos). Houve 3 casos ( $20 \%$ ) por acidente vascular encefálico (AVE), 3 (20\%) por baixo débito cardíaco, 2 (13,3\%) por rejeição, $2(13,3 \%)$ por sepsis, $2(13,3 \%)$ por coagulopatia, $2(13,3 \%)$ por hipertensão arterial pulmonar (HAP) e 1 caso (6,7\%) por morte súbita. Dos casos de AVE, 2 foram isquêmicos, com os pacientes evoluindo em coma precoce, e o terceiro provavelmente hemorrágico, súbito, em paciente com plaquetopenia severa e persistente, no $27^{\circ}$ dia de pós-operatório ( $\mathrm{PO}$ ). Dos três pacientes que faleceram de conseqüências do baixo débito cardíaco, um era transplante heterotópico, e evoluíram com choque persistente no $\mathrm{PO}$ precoce. Houve dois casos de rejeição, sendo uma hiperaguda e outra no 9 dia de pós-transplante. Dos dois óbitos por septicemia, ambos sem foco infeccioso aparente, um ocorreu no $12^{\circ} \mathrm{PO}$ e o outro no $18^{\circ}$ PO. A coagulopatia foi a causa de dois óbitos, 
Assef M A S, Valbuena P F M F, Neves Jr. M. T, Correia E B, Vasconcelos M, Manrique R, Magalhães H M, Souza L C B, Chaccur $P$, Dinkhuysen J J - Transplante cardíaco no Instituto Dante Pazzanese de Cardiologia: análise da sobrevida. Rev Bras Cir Cardiovasc 2001; 16(4): 289-304

sendo um deles em paciente com cirurgia cardíaca prévia; em ambos, mesmo após a revisão cirúrgica, persistiu a hemorragia, mantendo-se os exames de coagulação com grandes distúrbios. Dois óbitos tiveram como causa a hipertensão arterial pulmonar de difícil controle, que levou à disfunção do enxerto, ambos falecendo no $3^{\circ} \mathrm{PO}$. Finalmente, uma paciente teve morte súbita no 6응 $P O$, sendo que exame clínico realizado minutos antes não apresentava anormalidades.

A mortalidade após 30 dias e antes do primeiro ano foi de $8,75 \%$ (8 casos). Três foram relacionados com causas infecciosas; o primeiro (caso inicial de nossa casuística) era diabético, e, com o uso de corticoesteróide, houve descompensação do diabete, evoluindo posteriormente com abscesso escrotal e peritonite, com óbito no $81^{\circ} \mathrm{PO}$; o segundo foi $\mathrm{O}$ outro caso de transplante heterotópico, que faleceu no 48 $\mathrm{PO}$, sendo descoberta mediastinite em achado de necropsia; o terceiro faleceu de pneumocistose no $5^{\circ}$ mês de PO. Uma paciente faleceu por AVE no $8^{\circ}$ mês, sendo que já no $\mathrm{PO}$ imediato, após crise hipertensiva, apresentou lesão neurológica com seqüelas graves, levando à convulsões freqüentes e à intubação prolongada. Em uma paciente constatou-se infarto agudo do miocárdio no $3^{\circ}$ mês de $\mathrm{PO}$, cuja necropsia também diagnosticou rejeição grave. Dois pacientes apresentaram no $3^{\circ}$ mês de PO o baixo débito cardíaco como causa do óbito; um, após uma biópsia miocárdica que não apresentava rejeição, evoluiu com importante disfunção ventricular ao ecocardiograma, e o outro após uma operação de plastia tricuspídea, para correção de uma insuficiência tricúspide severa pós-transplante.

Após um ano de transplante, a mortalidade foi menor ( 7 casos). Destes, houve 2 casos por AVE, 1 por abandono do tratamento, 1 pela IRA, 1 por morte súbita, 1 por reativação da Tb e ao IAM em 1 caso. Ambos os casos de AVE apresentavam hipertensão arterial moderada; um teve um AVE isquêmico no $1^{\circ}$ mês de $\mathrm{PO}$ e o outro um AVE hemorrágico no $1^{\circ}$ ํㅡㅅ de $\mathrm{PO}$, tendo sido operado da hemorragia cerebral, mas vindo a falecer. Uma paciente passou a inalar cocaína, e abandonou o tratamento imunossupressor; morreu de rejeição no $02^{\circ}$ ano de evolução. O paciente que morreu por IAM no $7^{\circ}$ ano pós transplante apresentava cinean-giocoronariografia normal de dois anos antes. O paciente que faleceu de IRA ( pelo uso da ciclosporina) já se encontrava em programa de diálise durante $05^{\circ}$ ano de PO.

Comparando-se com dados da literatura $(7,10,22)$, podemos ver que 22 dos 23 óbitos deste estudo durante o primeiro ano de $\mathrm{PO}$ ocorreu nos primeiros seis meses $(97,5 \%)$; as causas principais relatadas no registro da International Society for Heart and Lung Transplantation de $1999^{\text {(7) mos- }}$ tram a infecção e a rejeição (e daí a importância da maior freqüência de biópsias endo-miocárdicas no primeiro ano) com as maiores incidências durante o primeiro ano de $\mathrm{PO}$, embora tenhamos tido 4 casos de óbito por causas neurológicas, como também observado na casuística da Universidade Federal de São Paulo (10), mas não em relatos internacionais. Cabe lembrarmos dos casos de baixo débito cardíaco, que também são freqüentes no primeiro mês de $P O$, provavelmente devido à incapacidade do novo órgão em se adaptar à hipertensão pulmonar do receptor $(19,22)$.

Os óbitos tardios relacionam-se, na maioria das vezes, com a doença arterial, não só do enxerto $(38,39)$, mas sistêmica, pelos efeitos da hipertensão arterial, hiperlipidemia e obesidade, fatores freqüentes de morbidade tardia. Por este fato, a cineangiocoronariografia, e mais recentemente o ultrasom coronariano, pela maior facilidade em detectar lesões entre a íntima e a média da parede da coronária (40) é realizado anualmente em nosso Serviço. Não ocorreu óbito por neoplasia, embora seja causa comum $(7,19)$.

Em relação à morbidade relacionada com a cirurgia ou com a medicação imunossupressora, nos pacientes vivos, temos: 2 pacientes com AVE (um com seqüela motora discreta e outro com distúrbio cognitivo; recentemente este último foi submetido à endarterectomia de carótida interna, pois ela apresentava lesão severa e a outra estava ocluída), 2 com lesões coronarianas moderadas a importantes (um já foi submetido à angioplastia coronariana), 2 com necrose da cabeça do fêmur pelo uso de corticoesteróides, 1 com marcapasso definitivo, 1 com cirrose hepática assintomática, $1 \mathrm{com}$ pericardite constrictiva (foi submetido à pericardiectomia, sem intercorrências), um com câncer de pele, dois com cálculos biliares (ambos operados), um com mediastinite e outro com infecção de parede torácica( ambos operados, sem intercorrências) e uma com hirsutismo(paciente de 7 anos). Um paciente foi vítima de trauma abdominal fechado, ficando com colostomia temporária por algumas semanas, tendo posteriormente seu trânsito intestinal reconstruído. Uma paciente teve adenoma na mama, que foi retirado cirurgicamente. Disfunção renal pós-transplante ocorreu em $28,7 \%$ de nossos casos e obesidade em $20,0 \%$.

Todos os 50 pacientes vivos se encontram livres de sintomas de ICC; muitos deles estão trabaIhando, e apresentam atividade física normal.

Após esta análise retrospectiva, podemos ver que o programa de transplante cardíaco mundial caminha para que cada vez mais o foco principal do objetivo deste procedimento seja alcançado: a melhora da sobrevida nos doentes com ICC grave. 
Assef M A S, Valbuena P F M F, Neves Jr. M. T, Correia E B, Vasconcelos M, Manrique R, Magalhães H M, Souza L C B, Chaccur P, Dinkhuysen J J - Transplante cardíaco no Instituto Dante Pazzanese de Cardiologia: análise da sobrevida. Rev Bras Cir Cardiovasc 2001; 16(4): 289-304

Contribuindo para isso, novas drogas imunossupressoras estão sendo descobertas para o controle de rejeição, com menores efeitos colaterais, como também a doença coronária do enxerto é mais rapidamente diagnosticada e combatida. Entretanto, este avanço esbarra na falta de doadores; atualmente não só pacientes com baixa expectativa de vida em seis meses, mas também aqueles com expectativa inferior a $50 \%$ em dois anos estão sendo colocados em filas de espera ${ }^{(41)}$, como também há deficiência de uma política adequada à doação de órgãos, com campanhas que alertem a população para tal problema. Devido a isto, estima-se que entre $20 \%$ e $40 \%$ dos pacientes selecionados para transplante venham a falecer na fila de espera ${ }^{(42)}$. No IDPC, este índice é em torno de $20 \%$.

Para tentar resolver o problema da carência de órgãos, além das tentativas da produção de animais transgênicos, e neste caso o que se mais investiga atualmente é o xenotransplante de porco, a utilização de dispositivos de assistência circulatória mecânica muitas vezes é a única possibilidade de sobrevida durante a espera do doador para aqueles que apresentam progressão da falência circulatória (43), lembrando que em alguns casos tais dispositivos chegam até a serem retirados com a melhora clínica da ICC.

Para os casos em que o transplante é indicado, mas que apresentam contra-indicação para este procedimento, o que ocorre em cerca de $50 \%$ dos candidatos (44), alternativas cirúrgicas devem ser cogitadas; entre elas, a cardiomioplastia (utilizando o músculo latissimus dorsi) e a ventriculectomia parcial do ventrículo esquerdo. Entretanto, a primeira técnica apresenta sobrevida a longo prazo inferior à do transplante, principalmente para pacientes operados em classe funcional IV da NYHA, enquanto que na segunda a sobrevida imediata e no primeiro ano tem sido limitada pela elevada incidência de progressão da insuficiência cardíaca e de óbitos relacionados a arritmias (44).
Verifica-se, portanto, que o transplante cardíaco humano, nestes quase 33 anos de evolução, transformou-se em terapêutica consagrada para a grande parte dos doentes com ICC grave, sendo que tais avanços que estão por vir poderão simplificar sua aplicação e melhorar cada vez mais a sobrevida.

Contudo, devemos sempre lembrar, como ressalta SHAPIRO ${ }^{(45)}$, que o transplante cardíaco não pode ser considerado evento isolado, mas sim um processo de segmento contínuo por toda vida do paciente, e para tanto uma equipe multidisciplinar é imprescindível na melhora da qualidade e expectativa de vida do transplantado, reintegrando-o no âmbito de família e sociedade.

\section{CONCLUSÕES}

A sobrevida a curto e a longo prazo dos pacientes submetidos ao transplante cardíaco no IDPC mostrou resultados semelhantes a de outros centros transplantadores nacionais e internacionais.

Fatores prognósticos na sobrevida relacionados aos doadores foram a idade acima de 40 anos, principalmente no sexo feminino, e acidente vascular isquêmico/hemorrágico como causa da morte encefálica, sendo a associação destes três fatores a de pior prognóstico.

Receptores com operação cardíaca prévia apresentaram maior mortalidade precoce, relacio-nados à coagulopatia e distúrbios vasculares neurológicos.

Esta análise de fatores de risco pode vir a ajudar na melhor seleção de doadores e receptores, e direcionar novas investigações científicas no campo do transplante cardíaco. 
Assef M A S, Valbuena P F M F, Neves Jr. M. T, Correia E B, Vasconcelos M, Manrique R, Magalhães H M, Souza L C B, Chaccur $P$, Dinkhuysen J J - Transplante cardíaco no Instituto Dante Pazzanese de Cardiologia: análise da sobrevida. Rev Bras Cir Cardiovasc 2001; 16(4): 289-304

RBCCV 44205-557

Assef M A S, Valbuena P F M F, Neves Jr. M. T, Correia E B, Vasconcelos M, Manrique R, Magalhães H M, Souza L C B, Chaccur P, Dinkhuysen J J - Heart transplantation at Instituto Dante Pazzanese de Cardiologia: analysis of survival. Rev Bras Cir Cardiovasc 2001; 16(4): 289-304

ABSTRACT: From November 30, 1991 to August 31, 2000, 80 cardiac transplants have been analyzed retrospectively at Instituto Dante Pazzanese de Cardiologia. Seventy percent of the recipient were male, and the recipient average was 44.8 years(range: 7 to 69 years). Twelve patients(15\%) were considered priority, receiving inotropic drug support at the moment of transplantation. The diagnosis of the recipients included primary dilated cardiomiopathy $(37.5 \%)$, ischemic cardiomiopathy (33.75\%), cardiomiopathy by Chagas disease $(17.5 \%)$ and others $(11.25 \%)$. Seventy eight transplants were orthotopic, and two heterotopic. Surgical technique used was bicaval/bipulmonar (63.75\%), atrial $(27.5 \%)$, bicaval/unipulmonar $(6.25 \%)$ and heterotopic (2.5\%). The 30 day mortality for all patients was $18.75 \%$. The survival after orthotopic transplant in one year was of $72.7 \%$; in five years was $61.5 \%$, and in seven years was of $56.4 \%$. The survival after transplant was related to the following variables: age, cause of death and sex of the donor, and wheter the transplant was or not the patient's first cardiac surgery.

DESCRIPTORS: Heart transplantation, methods. Heart transplantation, mortality. Heart transplantation, statistics \& numerical data.

\section{REFERÊNCIAS BIBLIOGRÁFICAS}

1 Barnard C N - A human cardiac transplant: an interim report of a successful operation performed at Groote Schuur Hospital, Cape Town. S Afr Med J 1967; 41: 1271-4.

2 Lower P R \& Shumway N E - Studies on the orthotopic homo-transplantation of canine heart. Surg Forum 1960; 11: 18-9.

3 Caves P K, Stinson E B, Billingham M E, Shumway N E - Serial transvenous biopsy of the transplanted human heart: improved management of acute rejection episodes. Lancet 1974; 1: 821-6.

4 Oyer $\mathrm{P}$ E, Stinson E B, Jamieson S W et al. Cyclosporin-A in cardiac allografting: a preliminary experience. Transplant Proc 1983; 15: 1219-59.

5 Mudge G H, Goldstein S, Addonizio L J et al. - Task Force 3: Recipient Guidelines? Prioritization. J Am Coll Cardiol 1993; 22: 1-64.

6 Trento A, Takkenberg J M, Czer L S C et al. - Clinical experience with one hundred consecutive patients undergoing orthotopic heart transplantation with bicaval and pulmonary venous anastomoses. J Thorac Cardiovasc Surg 1996; 112: 1496-503.

7 Hosenpud J D, Bennett L E, Keck B M, Fiol B, Boucek M $M$, Novick R J - The registry of the International Society for Heart and Lung Transplantation: sixteenth official report-1999. J Heart Lung Transplant 1999; 18: 611-26.

8 Moreira M C V, Magalhães H M, Bordignon S - III: Orientação para receptor. Arq Bras Cardiol 1999; 73: 12-20.
9 Dinkhuysen J J, Neves Jr. M T, Petrucci Jr. O, Oliveira C I C, Lima L L - VIII. Orientação e critérios para seleção do doador. Arq Bras Cardiol 1999; 73: 52-5.

10 Branco J N R, Teles C A, Aguiar L F et al. - Transplante cardíaco ortotópico: experiência na Universidade Federal de São Paulo. Rev Bras Cir Cardiovasc 1998; 13: $285-94$

11 Johson M R, Naftel D C, Hobbs R E et al. - The incremental risk of female sex in heart transplantation: a multiinstitutional study of peripartum cardiomyopathy and pregnancy. J Heart Lung Transplant 1997; 16: 801-12.

12 Aravot D T, Banner N R, Khaghani A et al. - Cardiac transplantation in the seventh decade of live. $A m \mathrm{~J}$ Cardiol 1989; 63: 90-3.

13 Correia E B, Dias da Silva M A - In: Dias da Silva MA, ed. Doenças do miocárdio. São Paulo: Sarvier, 1995. 217.

14 Bocchi E A - Situação atual das indicações e resultados do tratamento cirúrgico da insuficiência cardíaca. Arq Bras Cardiol 1994; 63: 523-30.

15 Massie B M \& Conway M - Survival of patients with congestive heart failure: past, present and future prospects. Circulation 1987; 75(5 pt 2): 11-9.

16 Likoff M J, Chandler S L, Kay H R- Clinical determinants of mortality in chronic congestive heart failure secondary to idiopathic dilated or to ischemic cardiomyopathy. Am J Cardiol 1987; 59: 634-8.

17 Cohn J N, Archibald D G, Ziesche S et al. - Effect of vasodilatador therapy on mortality in chronic congestive heart failure: results of a Veterans Administration Cooperative Study. N Engl J Med 1986; 314: 1547-52. 
Assef M A S, Valbuena P F M F, Neves Jr. M. T, Correia E B, Vasconcelos M, Manrique R, Magalhães H M, Souza L C B, Chaccur P, Dinkhuysen J J - Transplante cardíaco no Instituto Dante Pazzanese de Cardiologia: análise da sobrevida. Rev Bras Cir Cardiovasc 2001; 16(4): 289-304

18 Brandt M, Koch M T, Steinhoff G et al. - Do long-term results justify bridging to heart transplantation in patients with multi-organ dysfunction? Thorac Cardiovasc Surg 1996; 44: 277-81.

19 Hosenpud J D, Novick R J, Breen T J, Keck B, Daily P- The Registry of the International Society for Heart and Lung Transplantation: twelfth official report-1995. J Heart Lung Transplant 1995; 14: 805-15.

McGregor C G A, Jamieson S W, Oye P E - Heart transplantation at Stanford University. Heart Transplant 1984; 4: 30-9.

21 Stolf N A G - Transplante cardíaco humano no Brasil. Arq Bras Cardiol 1994; 63: 247-50.

Bourge R C, Naftel D C, Constanzo-Nordin M et al. Pretransplantion risk factors for death after cardiac transplantation: a mult-institutional study. J Heart Lung Transplant 1993; 12: 549-62.

Webb W R, Howard H S, Neely W A - Practical method of homologous cardiac transplantation. J Thorac Surg 1959; 37: 361-6.

Cass M H \& Brock R - Heart excision and replacement. Guy's Hosp Rep 1959; 108: 285-90.

Yacoub M, Mankad P, Ledingham S - Donor procurement and surgical techniques for cardiac transplantation. Semin Thorac Cardiovasc Surg 1990; 2: 153-61.

Dreyfus G, Jebara V, Mihaileanu S, Carpentier A F Total orthotopic heart transplantation: an alternative to standart technique. Ann Thorac Surg 1991; 52: 1181-4.

Blanche C, Czer L S, Valenza M, Trento A - Alternative technique for orthotopic heart transplantation. Ann Thorac Surg 1994; 57: 765-7.

Trento A, Czer L S C, Blanche C - Surgical techniques for cardiac transplantation. Semin Thorac Cardiovasc Surg 1996; 8:126-32.

Chaccur P, Dinkhuysen J J, Nina V J S et al. - Transplante cardíaco ortotópico pela técnica bicaval. Rev Bras Cir Cardiovasc 1997; 12: 145-52.

El Gamel A, Yonan N A, Grant S et al. - Orthotopic cardiac transplantation: a comparison of standart and bicaval Wythenshawe techniques. J Thorac Cardiovasc Surg 1995; 109: 721-30.

31 Blanche C, Czer L S C, Trento A et al. - Bradyarrhythmias requiring pacemaker implantation after orthotopic heart transplantation: association with rejection. $J$ Heart Lung Transplant 1992; 11: 446-52.
32 Brandt M, Harringer N, Hirt SN - Bicaval vs right atrial anastomosis in heart transplantation. $J$ Heart Lung Transplant 1996; 15: S 51(Abstract).

33 Kendall S W, Ciulli F, Mullins P A et al. - Total orthotopic heart transplantation: an alternative to the standard technique. Ann Thorac Surg 1992; 54: 187-8(letter).

34 Freimark D, Czer L S C, Aleksic I et al. - Improved left atrial transport and function with orthotopic heart transplantation by bicaval and pulmonary venous anastomoses. Am Heart J 1995; 130: 121-6.

35 Silva J P, Baumgratz J F, Vila J H A, Canêo L F Transplante cardíaco heterotópico. Rev Soc Cardiol Estado de São Paulo 1995; 5: 707-13.

36 Miller L W, Schlant R C, Kobashigawa J, Kubo S, Renlund D L - Task Force 5: complications. J Am Coll Cardiol 1993; 22: 41-54.

37 Sarris G E, Moore K A, Schroeder J S et al. - Cardiac transplantation: the Stanford experience in the cyclosporine era. J Thorac Cardiovasc Surg 1994; 108: $240-52$.

38 Hosenpud J D, Shipley G D, Wagner C R - Cardiac allograft vasculopathy: current concepts, recent developments and future directions. J Heart Lung Transplant 1992; 11: 9-23.

39 Miller L W - Transplant coronary artery disease. J Heart Lung Transplant 1992; 11: S1-4.

40 Valantine H, Pinto F J, St Goar F G et al. - Intracoronary ultrasound in cardiac transplant recipients. In vivo evidence of "angiographically silent" intimal thickening. Circulation 1992; 85: 879-87.

41 Stevenson L W, Dracup K A, Tilliach J H - Efficacy of medical therapy tailored for severe congestive heart failure in patients transferred for urgent cardiac transplantation. Am J Cardiol 1988; 58: 1046-50.

42 Stevenson L W, Warner S L, Steimle A E et al - The impending crisis awaiting cardiac transplantation: modeling a solution based on selection. Circulation 1994; 89: 450-7.

43 Leirner A A, Pêgo-Fernandes P M - Ponte para transplante cardíaco. In: Nesralla I, ed. Cardiologia cirúrgica: perspectivas para o ano 2000. São Paulo: Ed. Byk, 1994. 651-67.

44 Stolf N, Moreira L F, Scanavacca M et al. - VI. Alternativas ou ponte para o transplante cardíaco. Arq Bras Cardiol 1999; 73: 38-44.

45 Shapiro P F - Life after heart transplantation. Prog Cardiovasc Dis 1990; 32: 405-18. 